\title{
HER2/Neu Distribution in Female Breast Cancer in Libya: Correlation with Clinicopathological Features and Survival
}

\author{
Abdalla O Jebriel ${ }^{1,2^{*}}$, Jens Huober ${ }^{3}$ and Fathi B Abdalla \\ ${ }^{1}$ Department of Medical Oncology, Misurata Cancer Center, Libya \\ ${ }^{2}$ Misurata University Medical school, Libya \\ ${ }^{3}$ Department of Gynecology, University of ULM, Germany \\ ${ }^{4}$ Department of pathology, Misurata Cancer Center, Libya
}

*Corresponding author: Abdalla O Jebriel, Department of Medical Oncology, Misurata Cancer Center, Libya

\begin{abstract}
Background: HER2 protein over-expression is of great importance to guide hormone therapy. The present study aimed to determine the HER2 status of Libyan women with breast cancer and evaluate the correlation of HER2 expression with some clinicopathological features as well as overall survival (OS).

Patients and methods: Data on 245 women with a diagnosis of breast cancer who were registered at the Misurata Cancer Center (MCC) in Libya from January 2004 to December 2012 were retrospectively studied. Patients' demographic and clinicopathological data were collected and immunohistochemistry testing for HER2 was performed on the formalin fixed paraffin-embedded blocks of breast tissue of these patients.

Results: The mean age of women at diagnosis was $46.7 \pm$ 12.4 years [range: $25-86$ years] and the majority of the patients were post-menopausal women $(57.1 \%)$. The majority of breast cancers were invasive ductal carcinoma (82.4\%) of grade $2-3(89 \%)$, stage $2-3(81.6 \%)$ and lymph node involvement $(65.3 \%)$. The tumors were large with an average size of $4.47 \pm 2.8 \mathrm{~cm}$. In total, $57.1 \%$ of the patients had tumors with negative HER2 expression, whereas $13.1 \%$ had HER2 overexpression. HER2 positivity was correlated with histological grade $(p=0.05)$, but not with family history $(p$ $=0.9)$, menopausal status $(p=0.2)$, histological type $(p=$ $0.5)$, tumor size $(p=0.4)$, clinical stage $(p=0.9)$, lymph node status $(p=0.8)$, metastatic location $(p=0.71)$, recurrence $(p=0.4)$, or status at last follow-up $(p=0.09)$. OS was significantly shorter in patients with higher tumor stage $(p$ $<0.0001)$, larger tumor size $(p=0.0001)$ and higher grade $(p=0.001)$, as well as those with systemic metastasis $(p<$ $0.0001)$. Longer survival rate seemed to be more associated with negative HER2 expression, despite data being not statistically significant.
\end{abstract}

Conclusions: These results support the systematic use of HER2 expression as a prognostic and predictive marker to identify patients who may benefit from chemotherapy or targeted therapy that will improve their survival.

\section{Keywords}

Breast cancer, Her2/neu, Immunohistochemistry, Prognostic factor

\section{Introduction}

Breast cancer remains the most commonly diagnosed cancer and the leading cause of cancer death among women worldwide. Breast cancer rates are increasing in nearly every region globally; in Libya, breast cancer ranks first among female cancer, accounting for $16 \%$ of all cancers and is responsible for 17.9 new cases in 100000 women annually. According to the latest estimates, 6.2 per 100000 women die of breast cancer in Libya each. At an early stage of the disease, breast cancer can be effectively treated in most women, but, unlike in Europe and America, more than half of patients (51\%) in Libya are diagnosed in advanced stages (stage 3 and 4), leading to worse prognosis and poor survival rates [1-7].

Breast cancer is recognized as a heterogeneous disease characterized by a varied spectrum of clinical, pathological and molecular features with different prognostic and therapeutic implications. The evaluation of estrogen receptor (ER), progesterone receptor (PR) and human epidermal receptor protein-2 (HER-2/neu)

Citation: Jebriel AO, Huober J, Abdalla FB (2021) HER2/Neu Distribution in Female Breast Cancer in Libya: Correlation with Clinicopathological Features and Survival. Int J Cancer Clin Res 8:149. doi. org/10.23937/2378-3419/1410149

Accepted: April 16, 2021: Published: April 18, 2021

Copyright: (C) 2021 Jebriel AO, et al. This is an open-access article distributed under the terms of the Creative Commons Attribution License, which permits unrestricted use, distribution, and reproduction in any medium, provided the original author and source are credited. 
status is routinely performed nowadays to inform the management and prognosis of breast cancer, as these hormone receptors were shown to have a great influence on clinical outcomes.

HER2 is transmembrane tyrosine kinase receptor protein encoded by HER2/neu, a proto-oncogene located on chromosome $17 q$; the protein mediates the growth, differentiation, and survival of cells [8,9]. Abnormalities of HER2 were shown to occur in about 15$20 \%$ of breast cancers [10]. HER2 protein over-expression is also of great importance to guide hormone therapy, predicting approximately $50-75 \%$ of response rate to hormone therapy. HER2 protein is usually used as an eligibility criterion for anti-HER2 therapy, such as trastuzumab, which has been shown to be an effective treatment for HER2-positive breast cancer, even in advanced stages [11].

Very few studies have been conducted to date on breast cancer in Libya and tumor phenotypic alterations in the Libyan population remain partly unknown, mainly because of irregular follow-up [12-14]. Since the biological nature of the disease and clinical outcome are closely inter-linked, assessment of HER2 status is of great importance to optimize therapy decision in patients with newly diagnosed breast cancer.

In the present study, we examined the HER2 status of patients with breast cancer by immunohistochemistry and evaluated its correlation with clinicopathological features, and overall survival (OS) rate.

\section{Methods}

\section{Patients}

This is a retrospective study conducted on tumor biopsies of 245 women with a diagnosis of breast cancer, who were registered at the Misurata Cancer Center [MCC] in Libya from January 2004 to December 2012. The patients' demographic and clinicopathological data were collected from medical records using a checklist including age, family history, tumor size, lymph nodal status, histological grade, and type of tumor.

\section{Immunohistochemistry (IHC) examination}

The immunohistochemical examination was conducted on $5 \mu \mathrm{m}$ breast tissue sections routinely stained on hematoxylin and eosin. Immunohistochemical (IHC) was performed on a Leica ${ }^{\circledR}$ BOND $^{\mathrm{TM}}$ staining platform using the Novocastra Epitope Retrieval Solution (Leica Biosystems Necastle Ltd.) according to the kit instructions.

Analysis and examination of HER2 expression was carried out by an expert pathologist and scored using the HER2 scoring criteria for breast cancer as follows: 0 : absence or partial membranous staining in $<10 \%$ of tumor cells, $1+$ : partial membranous staining in $>10 \%$ of tumor cells, 2+: complete but weak to moderate mem- branous staining in $>10 \%$ of tumor cells, $3+$ : complete and strongly positive membranous staining in $>10 \%$ of tumor cells. In determining the HER2 status, cases with HER2 negative expression were defined by scores of 0 or $1+$, whereas cases with HER2 overexpression were defined by scores of $3+$. Cases with a weakly positive score $(2+)$ were considered as HER2 equivocal expression and HER2 gene amplification was analyzed using fluorescence in situ hybridization (FISH) or chromogenic in situ hybridization (CISH) techniques.

\section{Statistical analysis}

Statistical analyses were performed using SPSS software packages for Windows, versions 19.0 [SPSS, Inc., Chicago, USA]. The continuous variables were summarized using descriptive statistics (e.g., median, range, frequency, and percentage). For survival analysis, Kaplan-Meier curves were plotted, and differences between the curves analyzed using the log-rank test. Pearson and Spearman's correlation tests were used for comparison between two variables. P-values below 0.05 were regarded as significant. Comparison of numerical variables was done by using chi-square test with likelihood ratio [LR], or Fischer's exact test to assess the significance of association between the variables. Student $t$-tests and ANOVA were also used to test differences between the groups.

\section{Results}

The clinicopathological characteristics of the 245 breast cancer patients included in the study are presented in Table 1 . The mean age of women at diagnosis was $46.7 \pm 12.4$ years [range: $25-86$ years] and the majority of the patients were post-menopausal women (57.1\%). The majority of breast cancers were IDC (82.4\%) of grade 2-3 (89\%), stage 2-3 (81.6\%) and lymph node involvement $(65.3 \%)$. The tumors were large with an average size of $4.47 \pm 2.8 \mathrm{~cm}$. In total, $57.1 \%$ of the patients had tumors with negative HER2 expression, whereas $13.1 \%$ had HER2 overexpression.

\section{Correlation of HER2 expression with clinicopatho- logical features}

HER2 status was analyzed in the whole group and in subgroups defined by histological type, histological grade, clinical stage, TNM stage, and lymph node status, as shown in Table 2. HER2 positivity was correlated with histological grade $(p=0.05)$ : higher HER2 expression was observed in tumors with higher histological grades and all of HER2 overexpressed carcinomas were grade 2 and grade 3 (Figure 1). No statistically significant correlation was observed between HER2 expression and family history $(p=0.9)$, menopausal status $(p=0.2)$, histological type $(p=0.5)$, tumor size $(p=0.4)$, clinical stage $(p=$ $0.9)$, lymph node status $(p=0.8)$, metastatic location ( $p$ $=0.71)$, recurrence $(p=0.4)$, or status at last follow-up $(p=0.09)$ (Table 2$)$. 
Table 1: Patient's clinicopathological features $(N=245)$.

\begin{tabular}{|c|c|c|}
\hline \multicolumn{2}{|l|}{ Clinicopathological variables } & \multirow{2}{*}{$\begin{array}{l}\text { Number of patients, } \mathbf{n}(\%) \\
13(5.3)\end{array}$} \\
\hline \multirow{3}{*}{ Family history (breast or ovarian cancer) } & Positive & \\
\hline & Negative & $112(45.7)$ \\
\hline & Unknown & $120(49.0)$ \\
\hline \multirow[t]{3}{*}{ Menopausalstatus } & Premenopausal & $140(57.1)$ \\
\hline & Postmenopausal & $104(42.4)$ \\
\hline & Unknown & $1(4)$ \\
\hline \multirow{3}{*}{ HER2 } & Positive & $32(13.1)$ \\
\hline & Negative & $140(57.1)$ \\
\hline & Unknown & $73(29.8)$ \\
\hline \multirow[t]{4}{*}{ HER2status } & Negative & $140(57.1)$ \\
\hline & Positive & $32(13.1)$ \\
\hline & Need FISH/CISH & $14(5.7)$ \\
\hline & Unknown & $59(24.1)$ \\
\hline \multirow{3}{*}{ Histopathology type } & IDC & $202(82.4)$ \\
\hline & Lobular & $24(9.8)$ \\
\hline & Other types & $19(7.8)$ \\
\hline \multirow{4}{*}{ Histopathology grade } & 1 & $9(3.7)$ \\
\hline & 2 & $119(48.6)$ \\
\hline & 3 & $99(40.4)$ \\
\hline & Unknown & $18(7.3)$ \\
\hline \multirow[t]{5}{*}{ Clinical stage } & Stage 1 & $13(5.3)$ \\
\hline & Stage 2 & $114(46.5)$ \\
\hline & Stage 3 & $86(35.1)$ \\
\hline & Stage 4 & $30(12.2)$ \\
\hline & Unknown & $2(0.8)$ \\
\hline \multirow[t]{5}{*}{ Tumor stage } & T1 & $24(9.8)$ \\
\hline & T2 & $141(57.6)$ \\
\hline & T3 & $47(19.2)$ \\
\hline & T4 & $23(9.4)$ \\
\hline & Unknown & $10(4.1)$ \\
\hline \multirow[t]{5}{*}{ Nodal stage } & NO & $75(30.6)$ \\
\hline & N1 & $93(38.0)$ \\
\hline & N2 & $56(22.9)$ \\
\hline & N3 & $11(4.5)$ \\
\hline & Unknown & $10(4.1)$ \\
\hline \multirow[t]{3}{*}{ Lymphnodestatus } & Positive & $160(65.3)$ \\
\hline & Negative & $75(30.6)$ \\
\hline & Unknown & $10(4.1)$ \\
\hline \multirow[t]{5}{*}{ NumberLNs } & 0 & $75(30.6)$ \\
\hline & $1-3$ & $60(24.5)$ \\
\hline & $4-9$ & $55(22.4)$ \\
\hline & $>9$ & $37(15.1)$ \\
\hline & Unknown & $18(7.3)$ \\
\hline \multirow[t]{3}{*}{ Metastases at diagnosis } & MO & $212(86.5)$ \\
\hline & M1 & $30(12.2)$ \\
\hline & Unknown & $3(1.2)$ \\
\hline \multirow{3}{*}{ Recurrence at follow-up (local or distant) } & Yes & $70(28.6)$ \\
\hline & No & $150(61.2)$ \\
\hline & $\begin{array}{l}\text { Primary metastasis at } \\
\text { diagnosis }\end{array}$ & $25(10.2)$ \\
\hline \multirow[t]{3}{*}{ Status at last follow-up } & Dead & $52(21.2)$ \\
\hline & Alive free of disease & $154(62.9)$ \\
\hline & Alive with disease & 39 (15.9) \\
\hline
\end{tabular}


Table 2: Analysis of HER2 overexpression sub-grouped according to clinicopathological variables $(\mathrm{N}=245)$.

\begin{tabular}{|c|c|c|c|c|c|}
\hline \multirow{2}{*}{\multicolumn{2}{|c|}{ Clinicopathological variables }} & \multirow{3}{*}{\begin{tabular}{|l|}
$\begin{array}{l}\text { Number of } \\
\text { patients, } \mathbf{N}\end{array}$ \\
97
\end{tabular}} & \multirow{2}{*}{\multicolumn{2}{|c|}{ HER2, n (\%) }} & \multirow{4}{*}{$\begin{array}{l}\mathbf{P}^{*} \\
0.9\end{array}$} \\
\hline & & & & & \\
\hline \multirow[b]{2}{*}{ Family history } & No & & \begin{tabular}{|l|} 
Negative \\
$61(88.4)$ \\
\end{tabular} & \begin{tabular}{|l|} 
Positive \\
$8(11.6)$ \\
\end{tabular} & \\
\hline & Yes & 10 & $16(88.9)$ & $2(11.1)$ & \\
\hline \multirow[b]{2}{*}{ Menopausal status } & Premenopausal & 124 & $79(56.4)$ & $22(68.8)$ & \multirow[b]{2}{*}{0.2} \\
\hline & Postmenopausal & 85 & $61(43.6)$ & $10(31.3)$ & \\
\hline \multirow{7}{*}{ Histological type } & IDC & 175 & $119(85)$ & $23(71.9)$ & \multirow{7}{*}{0.5} \\
\hline & ILC & 19 & $13(9.3)$ & $4(12.5)$ & \\
\hline & Medullary & 2 & 0 & 0 & \\
\hline & Papillary & 3 & $2(1.4)$ & $1(3.1)$ & \\
\hline & Tubular & 0 & 0 & 0 & \\
\hline & Mucinous & 4 & $2(1.4)$ & $2(6.3)$ & \\
\hline & Mixed & 6 & $4(2.9)$ & $2(6.3)$ & \\
\hline \multirow{3}{*}{ Histological grade } & Grade 1 & 6 & $6(4.4)$ & 0 & \multirow{3}{*}{0.05} \\
\hline & Grade 2 & 105 & $62(45.9)$ & $20(66.7)$ & \\
\hline & Grade 3 & 90 & $67(49.6)$ & $10(33.3)$ & \\
\hline \multirow{4}{*}{ Clinical stage } & Stage 1 & 11 & $7(5.1)$ & $2(6.3)$ & \multirow{4}{*}{0.9} \\
\hline & Stage 2 & 93 & $62(44.9)$ & $15(46.9)$ & \\
\hline & Stage 3 & 79 & $50(36.2)$ & $11(34.4)$ & \\
\hline & Stage 4 & 24 & $19(13.8)$ & $4(12.5)$ & \\
\hline \multirow{4}{*}{$\mathrm{T}$} & $\mathrm{T} 1$ & 21 & $16(12)$ & $2(6.5)$ & \multirow{4}{*}{0.4} \\
\hline & T2 & 122 & 78 (58.6) & $18(58.1)$ & \\
\hline & T3 & 40 & $30(22.6)$ & $6(19.4)$ & \\
\hline & $\mathrm{T} 4$ & 18 & $9(6.8)$ & 5 (16.1) & \\
\hline \multirow{4}{*}{$\mathrm{N}$} & No & 61 & $44(33.1)$ & $11(35.5)$ & \multirow{4}{*}{0.7} \\
\hline & N1 & 74 & $49(36.8)$ & $10(32.3)$ & \\
\hline & N2 & 55 & $34(25.6)$ & $7(22.6)$ & \\
\hline & N3 & 11 & $6(4.5)$ & $3(9.7)$ & \\
\hline \multirow{2}{*}{$\begin{array}{l}\text { Number of positive lymph } \\
\text { nodes }\end{array}$} & Negative & 61 & $44(33.1)$ & $11(35.5)$ & \multirow[b]{2}{*}{0.8} \\
\hline & Positive & 140 & 89 (66.9) & $20(64.5)$ & \\
\hline \multirow[t]{2}{*}{ Metastases } & MO & 182 & $118(86.1)$ & $28(87.5)$ & \multirow[b]{2}{*}{0.8} \\
\hline & M1 & 24 & $19(13.9)$ & $4(12.5)$ & \\
\hline \multirow{5}{*}{ Metastatic location } & Bone & 24 & $17(33.3)$ & $4(28.6)$ & \multirow{5}{*}{0.71} \\
\hline & Liver & 4 & $3(5.9)$ & 0 & \\
\hline & Lung & 13 & $7(13.7)$ & $2(14.3)$ & \\
\hline & Multi-organ & 33 & $21(41.2)$ & $6(42.9)$ & \\
\hline & Local recurrence & 4 & $3(5.9)$ & $2(14.3)$ & \\
\hline & Yes & 60 & $89(63.6)$ & $17(53.1)$ & \\
\hline Recurrence [local or distant] & No & 130 & $36(25.7)$ & $12(37.5)$ & 0.4 \\
\hline & Metastasis at diagnosis & 19 & $15(10.7)$ & $3(9.4)$ & \\
\hline Status at last follow-up & Death & 42 & $27(19.3)$ & $11(34.4)$ & 0.09 \\
\hline & Free & 134 & $90(64.3)$ & $19(59.4)$ & \\
\hline & Mets & 33 & $23(16.4)$ & $2(6.3)$ & \\
\hline
\end{tabular}

${ }^{*}$ The $p$-values refer to significance of difference between the subgroups. 


\section{Survival analysis}

The median survival time of the study population was 40 months. At the average follow-up time of $40 \pm$ 33.69 months, $62.6 \%$ of the patients were free from disease, whereas $28.6 \%$ had a recurrence and $21.2 \%$ died. The 1-year and 5-year overall survival (OS) rates were
$96 \%$ and $86 \%$, respectively (Table 1 ).

Analysis of OS rates by HER2 status showed a trend suggesting that patients with low or no HER2 expression had better survival than those with high expression, but the results were not statistically significant (Figure 2). OS was significantly shorter in patients with higher tu-

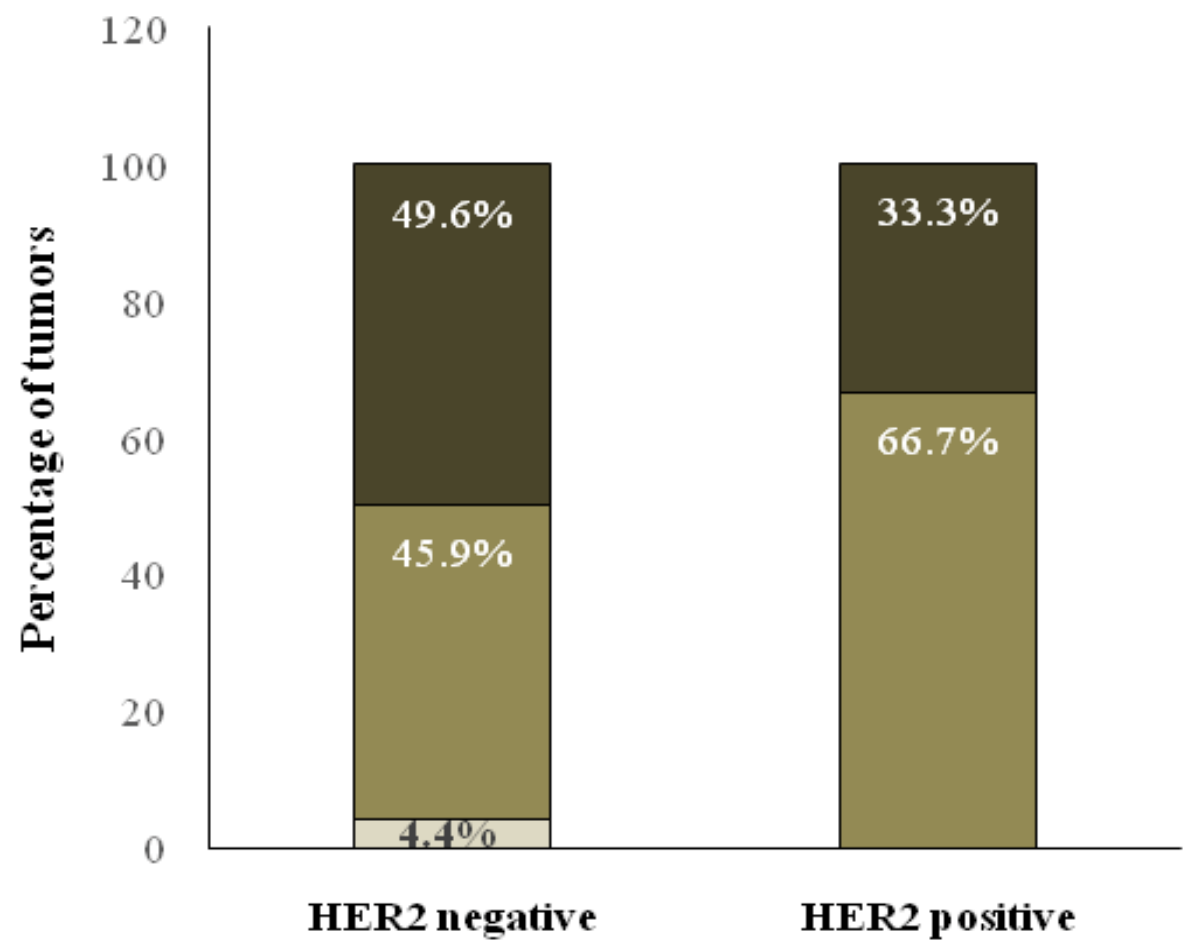

$\square$ Grade $1 \quad \square$ Grade $2 \square$ Grade 3

Figure 1: Correlation of HER2 expression with histological grade.

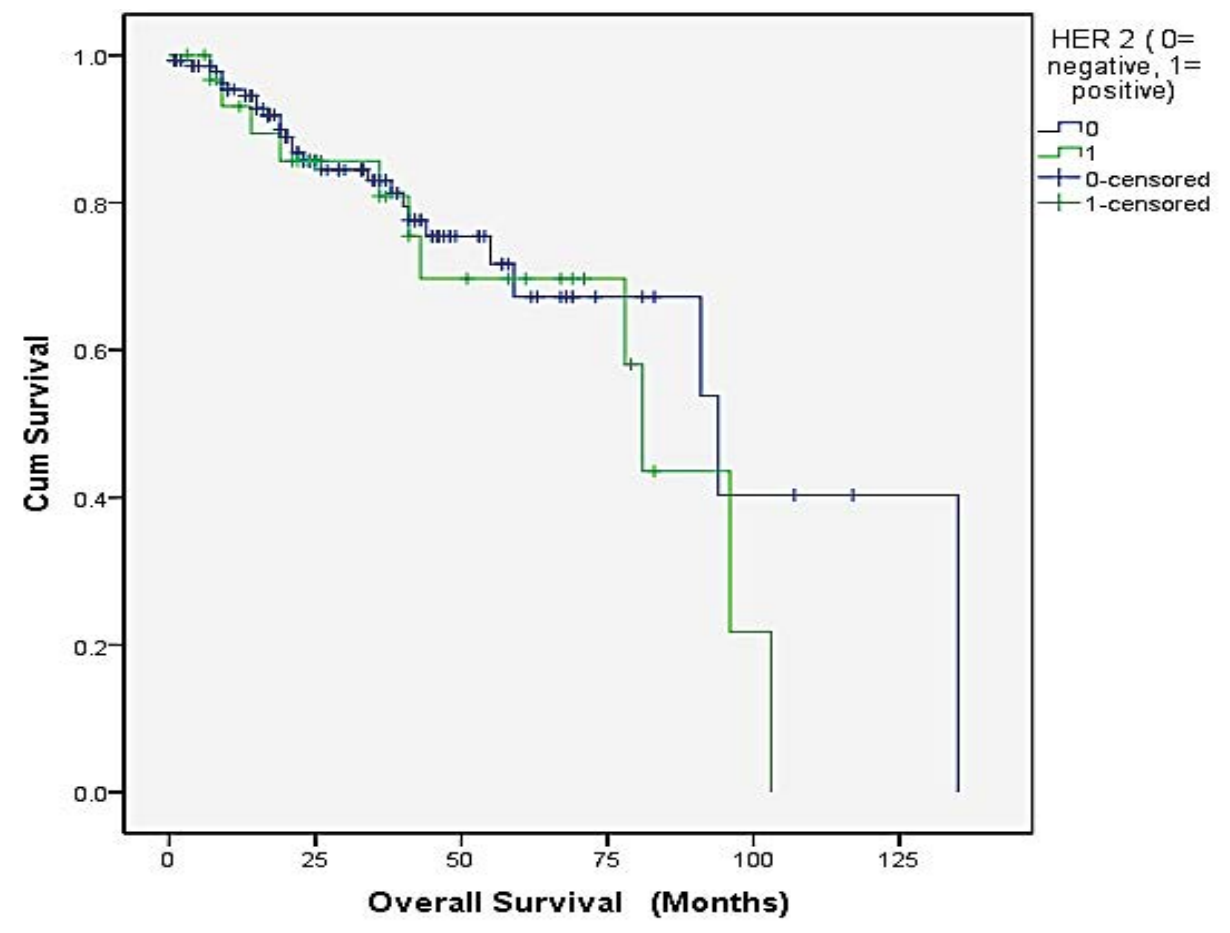

Figure 2: Kaplan-Meier estimates for overall survival according to HER2 expression. 

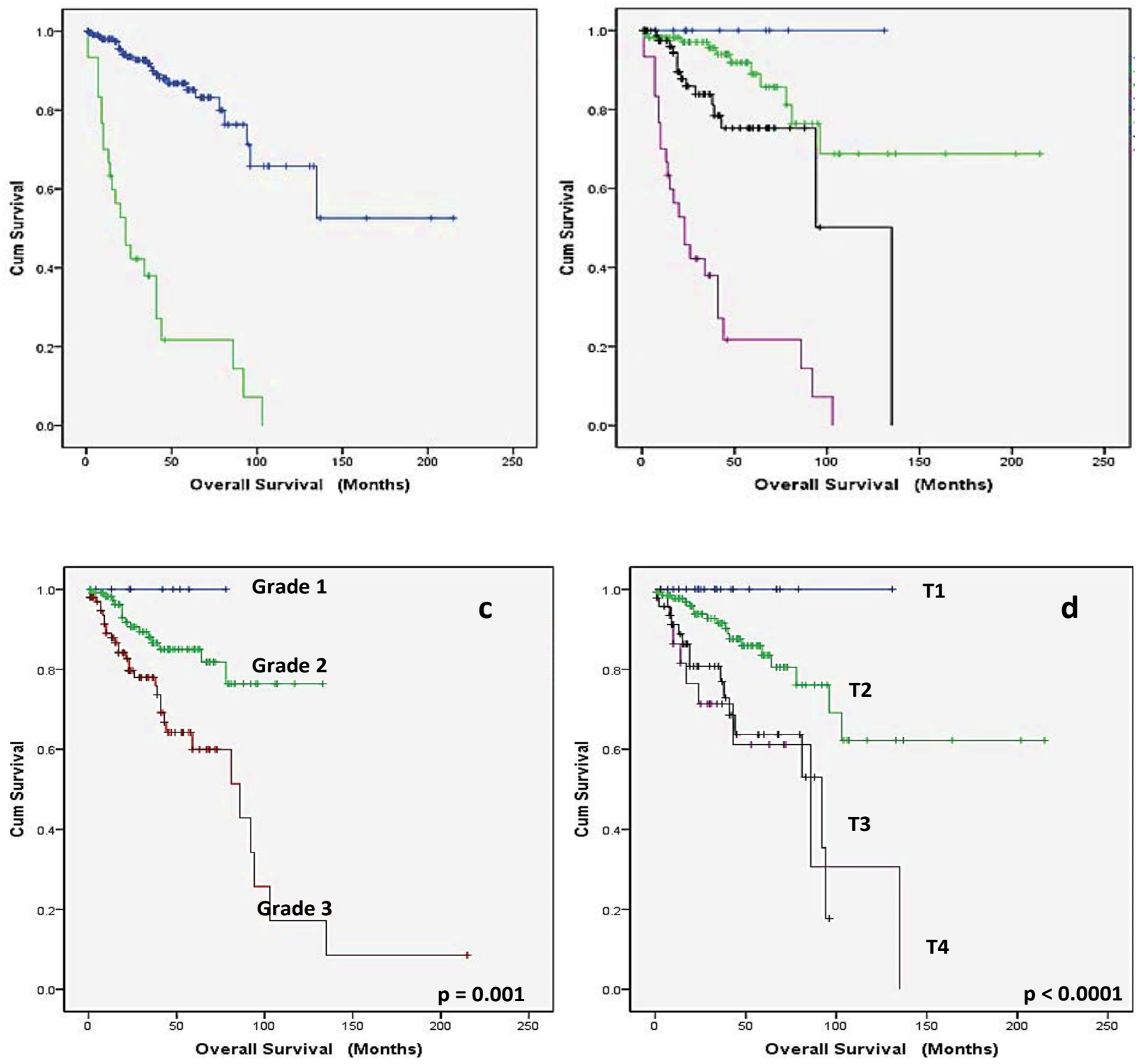

Figure 3: Kaplan Meier overall survival estimates according to: A) Systemic metastasis; B) Clinical stage; C) Histological grade; D) Tumorextent [T-stage].

mor stage $(p<0.0001)$, larger tumor size $(p=0.0001)$ and higher grade $(p=0.001)$, as well as those with systemic metastasis $(p<0.0001)$ (Figure 3$)$. In particular, better 10-year survival was observed in the subgroup of patients without metastasis, with stage 1 breast cancer, with histological grade 2 and grade 3 , and with a tumor size less than $2 \mathrm{~cm}$.

\section{Discussion}

Studying the frequency and the outcome of HER2 over-expressed breast cancer is of major importance to inform treatment strategies and better individualize targeted therapies in specific tumor subgroups with newly diagnosed breast cancers. Better knowledge of ethnic molecular features is important as considerable molecular differences were observed in cancers from various ethnical groups. The present study aimed to determine the HER2 status of Libyan women with breast cancer and evaluate the correlation of HER2 expression with some clinicopathological features as well as OS.

Our results show that HER2 is overexpressed in 13.1\% of newly diagnosed breast cancers in Libyan women. This figure is similar to the results obtained in other studies conducted among Middle Eastern and North African populations, where HER2 positivity was estimated at $17.5 \%$ in Jordan [15], 18.1\% in Tunisia [16], and $18.8 \%$ in Saudi Arabia [17]. A more recent study conducted in Saudi Arabia found a higher estimation of HER2 overexpression, with $29.9 \%$ positivity among Saudi women with newly diagnosed breast cancer from 2007 to 2013.

The findings of this study show that breast cancer is diagnosed in younger age groups (46 years), in more advanced stages, with features of aggressive behavior. Carcinomas with HER2 abnormalities are often associated with more aggressive features, such as high grade tumours, lymph node involvement, and a higher rate of disease recurrence and mortality $[11,18,19]$. In the pre- 
sent study, we found that tumors with HER2 positivity were significantly associated with higher tumor grade, consistently with Krishnaswamy, et al. [20]. Although, there was no statistically significant correlation between HER2 status and tumor size [ $p=0.4]$, the trend was similar to what was reported in previous studies where overexpression of HER2 was slightly more observed in patients with lower tumor size $(<5 \mathrm{~cm})[21,22]$.

Longer survival rate seemed to be more associated with negative HER2 expression, despite data being not statistically significant, consistently with findings from Hurley, et al. [23], and England, et al. [24].

In the present study, data was retrospectively collected from a single center in Libya, which could limit representativeness and generalizability of results, but also may have affected completeness of data. Although our study was not designed to estimate the prevalence of HER2 overexpression in the general population, we believe that the large period of clinical data collection (8 years from 2004 to 2012) provide baseline data of breast cancer features in Misurata region in Libya. Larger multicenter trials could be further planned to better genetically characterize breast cancer subgroups in Libya and estimate the actual frequency of HER2 overexpression in the general Libyan population with breast cancer.

\section{Conclusion}

In this study, HER2 overexpression was associated with higher tumor grade and HER2 negativity tended to correlate with better survival rate, in the absence of treatment. These results support the systematic use of HER2 expression as a prognostic and predictive marker to identify patients who may benefit from chemotherapy or targeted therapy that will improve their survival.

\section{Declarations}

\section{Funding}

The study was supported by the National Cancer Institute - Misurata (Libya).

\section{Conflicts of interest/Competing interests}

The authors declare no conflict of interest.

\section{Availability of data and material}

Data are available from the authors upon request.

\section{Ethical Approval}

The proposed study has been examined and approved by the ethics committee of Research Council of Misurata Cancer Center and informed consent was obtained from all the patients for enrollment in the trial and publication of this research.

\section{Acknowledgements}

The authors are grateful to the Misurata Cancer Cen- ter for their support for conducting this study and for providing data and other research facilities. The authors thank Dr. Emna El Hammi for providing medical writing assistance on behalf of INTO EVIDENCE.

\section{References}

1. Boder JME, Abdalla FE, Elfageih MA, Abusaa A, Buhmeida A, et al. (2011) Breast cancer patients in Libya: Comparison with European and central African patients. Oncol Lett 2: 323-330.

2. Kim J, Lee S, Bae S, Choi MY, Lee J, et al. (2012) Comparison between screen-detected and symptomatic breast cancers according to molecular subtypes. Breast Cancer Res Treat 131: 527-540.

3. Stapleton JM, Mullan PB, Dey S, Hablas A, Gaafar R, et al. (2011) Patient-mediated factors predicting early- and late-stage presentation of breast cancer in Egypt. Psychooncology 20: 532-537.

4. Chagpar $A B$, Crutcher $C R$, Cornwell LB, McMasters KM (2011) Primary tumor size, not race,determines outcomes in women with hormone-responsive breast cancer. Surgery 150: 796-801.

5. Rosen PP (2009) Breast pathology. Philadelphia, New York.

6. American Joint Committee on Cancer (2006) AJCC Cancer Staging Manual, ( $9^{\text {th }}$ edn) Springer, New York, 219-233.

7. Velikova G, Booth L, Johnston C, Forman D, Selby P (2004) Breast cancer outcomes in South Asian population of West Yorkshire. Br J Cancer 90: 1926-1932.

8. Kaufmann R, Müller P, Hildenbrand G, Hausmann M, Cremer C (2011) Analysis of HER2/neu membrane protein clusters in different types of breast cancer cells using localization microscopy. J Microsc 242: 46-54.

9. Gschwind A, Fischer OM, Ullrich A (2004) The discovery of receptor tyrosine kinases: Target for cancer therapy. Nat Rev Cancer 4: 361-370.

10. Bilous M, Dowsett M, Hanna W, Isola J, Moreno A, et al. (2003) Current perspective on HER2 testing. A review of national testing guidelines. Mod Pathol 16: 173-182.

11. Jalava PJ, Kuopio T, Kortelainen S, Kronqvist $P$, Collan $Y U$ (2002) Quantitation of erbB2 positivity for evaluation of high-risk patients. Ann Med 34: 544-553.

12. Abdalla FBE, Markus R, Buhmeida A, Boder J, Syrjänen K, et al. (2012) Estrogens receptors, progesterone receptors, and nuclear size features in Libyan female breast cancer: Correlation with clinical features and survival. Anticancer Res 32: 3485-3494.

13. El Mistiri M, Verdecchia A, Rashid I, El Sahli N, El Mangush, et al. (2003) Cancer incidence in eastern Libya: the first report from the Benghazi Cancer Registry. Int J Cancer 120: 392-397.

14. African Oncology Institute (2008) Sabratha Cancer Registry: First annual report, 2006 (1st edn) Sabratha, Libya, 1-64.

15. Sughayer MA, Al-Khawaja MM, Massarweh S, Al-Masri M (2006) Prevalence of hormone receptors and HER2/neu in breast cancer cases in Jordan. Pathol Oncol Res 12: 83-86.

16. Ayadi L, Khabir A, Amouri H, Karray S, Dammak A, et al. (2008) Correlation of HER-2 over-expression with clinico-pathological parameters in Tunisian breast carcinoma. World J Surg Oncol 6: 112. 
17. Arafah M (2012) Correlation of hormone receptors with Her-2 Neu protein expression and the histological grade in invasive breast cancers in a cohort of Saudi Arabia. Turk Patoloji Derg 28: 38-43.

18. Qiao E, Ji M, Wu J, Li J, Xu X, et al. (2013) Joint detection of multiple immunohistochemical indices and clinical significance in breast cancer. Mol Clin Oncol 1: 703-710.

19. Yeh ES, Yang TW, Jung JJ, Gardner HP, Cardiff RD, et al. (2011) Hunk is required for HER2/neu-induced mammary tumorigenesis. J Clin Invest 121: 866-879.

20. Krishnaswamy U, Balachandran P, Rajakumar I, Balachandar K, Mansoor M (2013) Correlation of Her-2 neu over-expression with clinico pathological features of carcinoma breast. Apollo Med 10: 313-317.

21. Panjwani $P$, Epari $S$, Karpate $A$, Shirsat $H$, Rajsekharan $P$, et al. (2010) Assessment of HER-2/neu status in breast cancer using fluorescence in situ hybridization \& immunohistochemistry: Experience of a tertiary cancer referral centre in India. Indian J Med Res 132: 287-294.

22. Azizun-Nisa, Bhurgri Y, Raza F, Kayani N (2008) Comparison of ER, PR and HER-2/neu (C-erb $B$ 2) reactivity pattern with histologic grade, tumor size and lymph node status in breast cancer. Asian Pac J Cancer Prev 9: 553-556.

23. Hurley J, Doliny P, Reis I, Silva O, Gomez-Femandez C, et al. (2006) Docetaxel, Cisplattin, and Trastuzumab As Primary Systemic Therapy for Human Epidermal Growth Factor Receptor 2-Positive Locally Advanced Breast Cancer. J Clin Oncol 24: 1831-1838.

24. Slamon DJ, Jones LB, Shak S, Fuchs H, Paton V, et al. (2001) Use of chemotherapy plus a monoclonal antibody against HER2 for metastatic breast cancer that overexpresses HER2. N Engl J Med 344: 783-792. 